STUDI

FRANCESI

\section{Studi Francesi}

Rivista quadrimestrale fondata da Franco Simone

179 (LX | II) | 2016

Varia

\title{
Bernard J. Bourque, All the Abbe's Women. Power and Misoginy in Seventeenth-Century France, through the Writings of Abbé d'Aubignac
}

\section{Laura Rescia}

\section{OpenEdition}

Journals

\section{Edizione digitale}

URL: http://journals.openedition.org/studifrancesi/4347

DOI: $10.4000 /$ studifrancesi.4347

ISSN: 2421-5856

\section{Editore}

Rosenberg \& Sellier

\section{Edizione cartacea}

Data di pubblicazione: 1 settembre 2016

Paginazione: 321

ISSN: 0039-2944

\section{Notizia bibliografica digitale}

Laura Rescia, «Bernard J. Bourque, All the Abbe's Women. Power and Misoginy in Seventeenth-Century France, through the Writings of Abbé d'Aubignac », Studi Francesi [Online], 179 (LX | II) | 2016, online dal 01 septembre 2016, consultato il 18 septembre 2020. URL : http://journals.openedition.org/ studifrancesi/4347; DOI : https://doi.org/10.4000/studifrancesi.4347

\section{Questo documento è stato generato automaticamente il 18 settembre 2020.}

\section{cc) $($ ) $\ominus$}

Studi Francesi è distribuita con Licenza Creative Commons Attribuzione - Non commerciale - Non opere derivate 4.0 Internazionale. 


\title{
Bernard J. Bourque, All the Abbe's Women. Power and Misoginy in Seventeenth-Century France, through the Writings of Abbé d'Aubignac
}

\author{
Laura Rescia
}

\section{NOTIZIA}

BERNARD J. BOURQUE, All the Abbe's Women. Power and Misoginy in Seventeenth-Century France, through the Writings of Abbé d'Aubignac, Tübingen, Gunter Narr Verlag, 2015, «Biblio 17», $224 \mathrm{pp}$.

1 Questo saggio si pone un duplice obiettivo: l'assunto di base, come emerge chiaramente dal titolo, è che sia possibile ricostruire, attraverso la lettura del corpus prescelto - le opere di d'Aubignac - la percezione del ruolo femminile nella società francese secentesca, e come questa fosse influenzata dagli avvenimenti socio-politici dell'epoca. La scelta di d'Aubignac, spiega l'autore, è dovuta sia alla centralità del suo ruolo nel panorama politico, istituzionale e culturale del suo tempo, sia alla ricchezza dei generi in cui si è cimentato - dal teatro al romanzo, dalla critica letteraria alla teoria drammaturgica.

2 Accanto a questo intento, di ordine storico e culturale, si esprime l'intenzione di contribuire alla conoscenza dell'opera dell'Abbé, spesso ridotta al più celebre dei suoi testi, quella Pratique du théâtre che l'edizione moderna di Hélène Baby ha reso da qualche anno di facile accesso.

3 Ne emerge un quadro d'insieme che rivela un atteggiamento oscillante di d'Aubignac, che sembra modulare e alternare affermazioni misogine a più favorevoli giudizi sulle donne, in particolare sulla possibilità di esercitare un ruolo negli affari di Stato, in base ad un opportunismo politico, dettato dalla necessità di ammansire la reggente di turno. 
Ma alternanze tra la voce protofemmista e quella marcatamente misogina sono altresì presenti all'interno di una stessa opera, come se l'autore desse voce a una pluralità identitaria, affiancando sulla scena letteraria il suo ruolo di religioso a quello di raffinato letterato frequentatore dei salons.

4 Se da un punto di vista metodologico potrà dispiacere l'assenza di riflessione sull'influenza delle diverse poetiche, quella teatrale in particolare, nel delineare i profili dei personaggi femminili, questo saggio ha il merito di permettere una scoperta o riscoperta di aspetti meno noti dell'opera di d'Aubignac, grazie a un'abbondante pratica citazionale e una ricca bibliografia primaria. Il taglio critico risente fortemente dell'influenza dei gender studies; e la bibliografia relativa a testi non appartenenti alla critica anglosassone avrebbe forse necessitato di un aggiornamento. 